\title{
An Assessment of Healthcare Workers Knowledge about COVID-19
}

\author{
Hadi J. Al Sulayyim 1*, Mohammed Chyad Al-Noaemi², Saleh M. Rajab', Hassan A. Daghriri², \\ Salem M. Al Yami' , Ali S. Al-Rashah1, Hussain M. Alsharyah', Saleh H. Al Murdif1, \\ Misfer H. Al Salom ${ }^{1}$
}

${ }^{1}$ Najran Health Affairs, Ministry of Health, Najran, KSA

${ }^{2}$ Al-Ghad International College of Applied Medical Sciences, Najran, KSA

Email: ^hadialsleem@hotmail.com

How to cite this paper: Al Sulayyim, H.J., Al-Noaemi, M.C., Rajab, S.M., Daghriri, H.A., Al Yami, S.M., Al-Rashah, A.S., Alsharyah, H.M., Al Murdif, S.H. and Al Salom, M.H. (2020) An Assessment of Healthcare Workers Knowledge about COVID-19. Open Journal of Epidemiology, 10, 220-234. https://doi.org/10.4236/ojepi.2020.103020

Received: May 28, 2020

Accepted: June 26, 2020

Published: June 29, 2020

Copyright $\odot 2020$ by author(s) and Scientific Research Publishing Inc. This work is licensed under the Creative Commons Attribution International License (CC BY 4.0).

http://creativecommons.org/licenses/by/4.0/

\begin{abstract}
Introduction: Coronavirus disease 2019 (COVID-19) is caused by a viral infection and considered the third coronavirus emerging among human beings over the past two decades. Healthcare Workers (HCWs) are at high risk of acquiring this serious infection during providing care to patients. Therefore, it's crucial to assess the knowledge of the HCWs about COVID-19. Methods: A multicenter cross-sectional study was conducted on HCWs working at public hospitals and Primary Healthcare (PHC) centers in the Najran region, KSA to evaluate the staff s knowledge toward COVID-19. The questionnaire consisted of two parts, the first part included the demographic data, and the second part involved questions related to the COVID-19. Results: 451 HCWs participated in this study and the median of overall knowledge score was $67 \%$. Most HCWs properly identified symptoms (82.9\%), mode of transmission $(78.5 \%)$, the incubation period $(96.4 \%)$, the way of preventing the infection (91.5\%), the COVID-19 is not same as MERS-CoV (74.3\%) and availability of a vaccine against the COVID-19 (82\%). However, HCWs were less likely to identify the source of COVID-19 when it was discovered in China (22.5\%), the mortality rate $(44.6 \%)$, and the presence of treatment $(32.1 \%)$. Overall knowledge score was statistically significantly associated with profession ( $\mathrm{P}=0.034)$, educational level $(\mathrm{P}=0.033)$, and availability of the infection control in the workplace $(P=0.006)$. Conclusion: The findings of this study demonstrated an intermediate level of knowledge of HCWs about COVID-19. Intervention programs are urgently needed to raise the knowledge of HCWs about this global public health issue.
\end{abstract}

\section{Keywords}

COVID-19, Knowledge, Healthcare Worker, Assessment, Najran 


\section{Introduction}

The human coronavirus ( $\mathrm{HCoV}$ ) was discovered in 1965 and was named as B814 [1]. HCoVs are classified within the family Coronaviridae (genus, Coronavirus) in the order Nidovirales. They are the largest RNA viruses, enveloped, nonsegmented, positive-sense, single-stranded RNA viruses, and named after their corona-like or crown-like surface projections seen on electron microscopy that correspond to large surface spike proteins [2] [3] [4].

$\mathrm{HCoVs}$ are widely distributed among birds and mammals as well as humans [5] [6]. There are six species of coronavirus that cause human illness. 229E, OC43, NL63, and HKU1 are typically associated with common cold symptoms [7]. The other two species are originally zoonotic, including severe acute respiratory syndrome (SARS-CoV) which was the related pathogen for SARS-CoV in Guangdong Province, China in 2002 and 2003 [8] [9] [10], and the Middle East respiratory syndrome (MERS-CoV) that was the causative agent for MERS-CoV in the Middle East, which was first diagnosed in Saudi Arabia in 2012 [11] [12].

In late December 2019, clusters of sick people with pneumonia of unknown reasons were discovered in Wuhan, Hubei Province, China. These cases were epidemiologically linked to the seafood wholesale market in Wuhan [13]. A new virus was identified and initially called the 2019 novel coronavirus (2019-nCoV) [6]. International Committee on Taxonomy of Viruses eventually changed the name of the virus to severe acute respiratory syndrome coronavirus 2 (SARS-CoV-2) [14]. On January 30, 2020, the World Health Organization (WHO) named the disease as "COVID-19" which is coronavirus disease 2019 [15]. Although COVID-19 outbroke in December 2019 in Wuhan (China), soon it spreads worldwide and in a couple of weeks the number of confirmed cases was reported by the majority of countries around the world, therefore, on March 11, 2020, the WHO officially described the COVID-19 outbreak as a pandemic [16].

In the Kingdome of Saudi Arabia (KSA), the first confirmed COVID-19 case was reported on 2nd March 2020 from Qatif, eastern region, a Saudi national person coming back from Iran across Bahrain. His companion was reported the second case on the 4th of March 2020 [17]. Since then and till now, about 35,000 positive cases were reported in almost all KSA cities [Saudi Ministry of Health] [18].

During the outbreak of coronaviruses such as SARS-CoV, MERS-CoV in the past, and COVID-19 in these days, many HCWs in the affected nations risked and lost their lives by treating patients. HCWs represent the frontline against any outbreak of endemic disease. The health authorities of China notified the WHO about the SARS-CoV outbreak on 10 February 2003, reporting 305 cases including 105 HCWs and five deaths [19]. On Feb 26, 2003, Carlo Urbani, an infectious diseases specialist in WHO's country office in Vietnam, was called to the French Hospital in Hanoi to examine a grievously ill Chinese-American businessman. Within days, nearly 40 people of the HCWs had fallen ill, and 
about seven of them died including Carlo Urbani [20]. On March 15, 2003, the WHO reported that the majority of SARS cases have occurred in people who have had very close contact with other cases and over $90 \%$ of cases have occurred in HCWs (WHO Report 16 March 2003) [21]. In 2004, Robert reported that there was a rapid spread of SARS in HCWs most notably in Toronto hospitals during the global outbreak of SARS in 2002-2003 contributed to dozens of identified cases, some of them fatal [22].

Despite the belief that $\mathrm{HCoV}$ has been transmitted from animals, it was anticipated that the first affected patients had been gotten the infection with SARS-CoV-2 via human to human infection [23]. Studies have demonstrated that human to human transmission of COVID-19 occurred via the droplet and direct contact with infected persons [24] [25] [26] [27]. Asymptomatic individuals cause a possibility of transmission of the COVID-19 infection [28].

Currently, there are no medical treatments for COVID-19 with proven effectiveness. Novel treatments and/or vaccines will take time to be developed and distributed to patients all over the world. In light of this, there has been growing interest in the urgent implementation of effective preventive strategies to lower the risk of transmission, [29] [30] [31]. Such preventive strategies include health information and advice for the general social population [32], vaccines against SARS-CoV-2 infection [29] [33] [34] preventive drugs therapy [35] [36], and improve knowledge and awareness among HCWs [37] [38] [39] [40].

Despite the availability of an enormous amount of information from different resources to community members as well as HCWs, a huge volume of this information is not evidence-based nor the best available resources. Therefore, it becomes very important to assess HCWs' knowledge of the pandemic against the best available information.

This study aims to assess the knowledge of HCWs in Najran, KSA about COVID-19.

\section{Methods}

A multicenter cross-sectional study conducted over 15 days period (1-15 April 2020) which surveyed staff working at public hospitals and PHCs in the Najran region, KSA. The HCWs included in this study were Physicians, Dentists, Pharmacists, Nurses, Laboratory staff, Radiologists, Respiratory therapists, EMTs, Ophthalmologists, Physiotherapists, Public health staff, infection prevention and control (IPC) staff, Social workers, psychologists and Dental technicians. All members of the above-mentioned staff categories in all public hospitals and PHC centers were invited via electronic link (SurveyMonkey), 451 HCWs participated in this study.

\section{Inclusion and exclusion criteria:}

Students, trainees, and administrative staff were excluded from this study. We included HCWs who work in the public hospitals and PHC centers such as Physicians, Dentists, Pharmacists, Nurses, Laboratory staff, Radiologists, Respiratory 
therapists, EMTs, Ophthalmologists, Physiotherapists, Public health staff, infection prevention and control (IPC) staff, Social workers, psychologists and Dental technicians.

\section{Ethical approval:}

This study was approved by the Institutional Review Board (IRB) committee of King Fahad Medical City, Riyadh, KSA (29.03.2020).

\section{Study tool:}

A validated questionnaire was adapted and modified to evaluate the healthcare staff's knowledge about COVID-19 [41]. A pilot study was done to ensure two things; applicability and time frame that is needed to complete the questionnaire (a group of 10 staff was tested). The questionnaire contained two parts. The first part included demographic data (age, gender, years of experience, profession, settings, educational level, and availability of infection control in their settings). The second part was composed of multiple-choice questions assessing HCWs knowledge about COVID-19 (what is COVID-19, mode of transmission, symptoms, incubation period, source of COVID-19 when was discovered, way of prevention, similarity to MERS-CoV, mortality rate, treatment, and vaccination).

Participants' knowledge was evaluated against published evidence and guidelines [17]-[22]. We calculated a total score for each participant according to their response. The total score was 12 .

\section{Statistical analysis:}

Median (inter-quartile range) and frequency (percent) were used to present the data. Mann-Whitney test and Kruskal Wallis were used to compare the data. Robust regression analysis was used to identify the factors associated with the overall knowledge score. For analyzing the data, statistical packages IBMSPSS (Version 20) was employed.

\section{Results}

There was a total of 451 participants in this study. The majority of the respondents were male $(61.2 \%)$, and $47 \%$ of the total participants were 25 to 34 years old, however, no one of them was 65+ years old. Most of the respondents were nurses $(40.5 \%)$ while the least were IPC staff. The median of the participant's experience was 9 (5 - 14) years, and nearly 86\% of respondents reported that they work at the hospital. Roughly $50 \%$ of the study respondents hold a bachelor's degree and only $2.2 \%$ of them had Ph.D. While $91.3 \%$ of participants reported that the IPC department is available at their workplace, about $5 \%$ of them did not know. The demographic data of the respondents are presented in Table 1.

Responses of HCWs about the COVID-19 are presented in Table 2. Most of the participants identified COVID-19 as coronavirus disease 2019 and $1.8 \%$ didn't have an idea of what does COVID-19 mean. While there was small variation among respondents in terms of the mode of transmission of the virus, the 
Table 1. Demographic characteristics of study participants.

\begin{tabular}{|c|c|c|c|}
\hline Variable & & $\mathbf{N}$ & $\%$ \\
\hline Experience, Median (Q1 - Q3) & & 9 & $(5-14)$ \\
\hline \multirow[t]{6}{*}{ Age group } & $18-24$ & 2 & 0.4 \\
\hline & $25-34$ & 212 & 47 \\
\hline & $35-44$ & 173 & 38.4 \\
\hline & $45-54$ & 48 & 10.6 \\
\hline & $55-64$ & 16 & 3.5 \\
\hline & $65+$ & 0 & 0 \\
\hline \multirow[t]{2}{*}{ Gender } & Male & 276 & 61.2 \\
\hline & Female & 175 & 38.8 \\
\hline \multirow[t]{6}{*}{ Profession } & Physician & 92 & 20.7 \\
\hline & Dentist & 21 & 4.7 \\
\hline & Nurse & 180 & 40.5 \\
\hline & Pharmacist & 26 & 5.9 \\
\hline & IPC & 12 & 2.7 \\
\hline & Other & 113 & 25.5 \\
\hline \multirow[t]{3}{*}{ Place of work } & Primary Health Care & 37 & 8.3 \\
\hline & Hospital & 384 & 85.7 \\
\hline & Regional Directorate & 27 & 6 \\
\hline \multirow[t]{6}{*}{ Educational-Level } & Diploma & 127 & 28.3 \\
\hline & Bachelor & 222 & 49.6 \\
\hline & Master & 57 & 12.7 \\
\hline & $\mathrm{PhD}$ & 10 & 2.2 \\
\hline & Board & 18 & 4 \\
\hline & Fellowship & 14 & 3.1 \\
\hline \multirow[t]{3}{*}{ Availability IPC at your settings } & Yes & 408 & 91.3 \\
\hline & No & 18 & 4 \\
\hline & Don't know & 21 & 4.7 \\
\hline
\end{tabular}

Table 2. Responses of participants about COVID-19.

\begin{tabular}{|c|c|c|c|}
\hline & lestion & $\mathbf{N}$ & $\%$ \\
\hline \multirow{4}{*}{ COVID-19 } & Corona virus disease 2019 & 306 & 68.5 \\
\hline & Viral respiratory illness & 11 & 2.5 \\
\hline & All answers are correct & 122 & 27.3 \\
\hline & No idea & 8 & 1.8 \\
\hline \multirow{4}{*}{ Transmission } & Droplet & 55 & 12.3 \\
\hline & Contact & 23 & 5.1 \\
\hline & Droplet \& Contact & 351 & 78.5 \\
\hline & Don't know & 18 & 4.0 \\
\hline
\end{tabular}




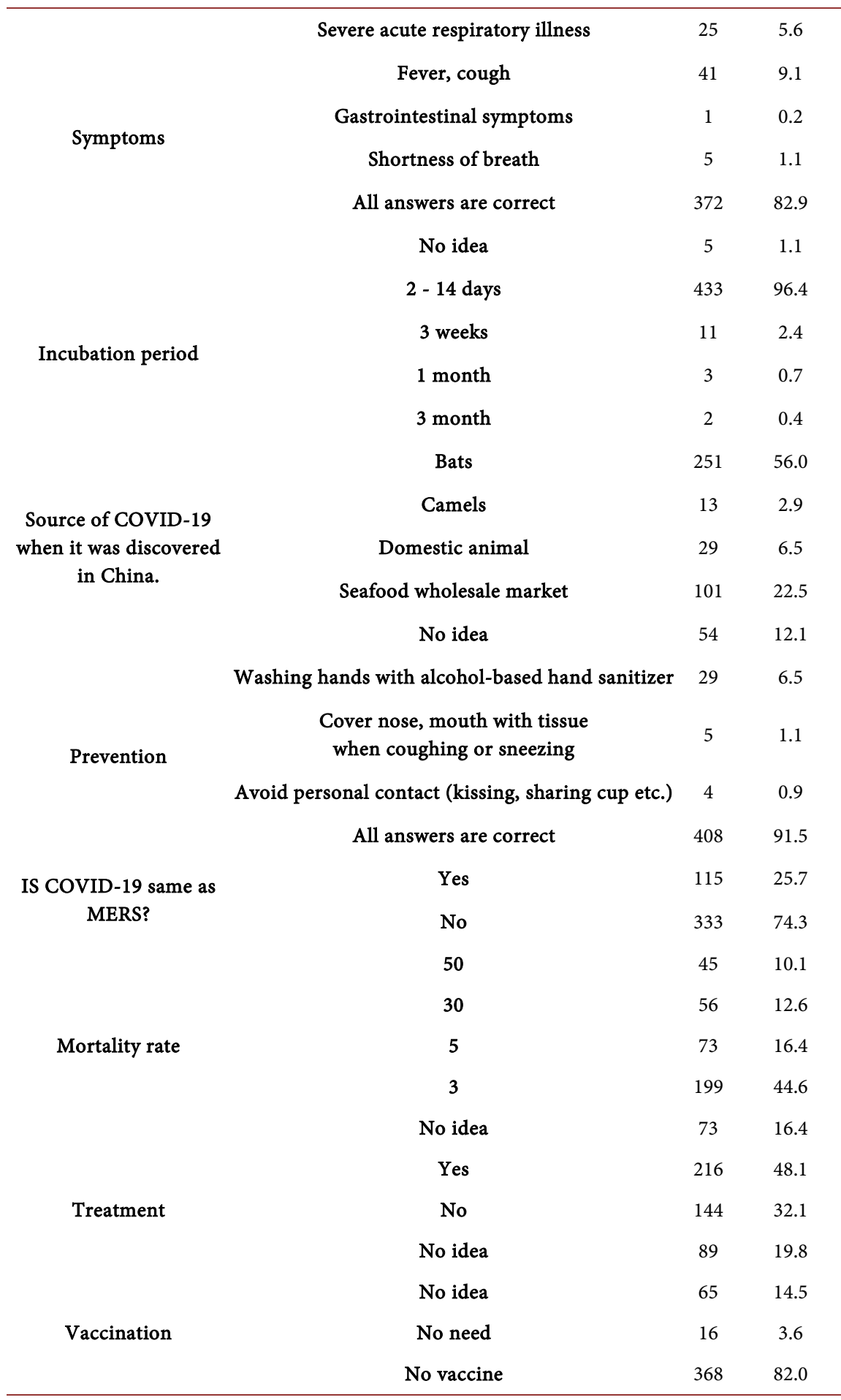

vast majority (78.5\%) reported droplet and contact are the way of the transmission. Approximately $83 \%$ of the respondents reported severe acute respiratory illness, cough, fever, gastrointestinal symptoms and shortness of breath are the symptoms, but $1.1 \%$ of them were unable to mention the symptoms. Between 2 and 14 days of the incubation period was reported by roughly $97 \%$ of the HCWs. 
Respondents were asked about the source of COVID-19 when it was discovered in China and over 55\% of them reported Bats. The HCWs were also asked regarding the way of prevention and the vast majority of them (91.5\%) mentioned washing hands with alcohol-based hand sanitizer, cover nose and mouth with a tissue when coughing or sneezing, and avoiding personal contact is the ways to prevent the infection.

Regarding similarity between COVID-19 and MERS-CoV, 25\% of the respondents stated that both viruses are same. The HCWs showed a variation with respect to mortality rate caused by COVID-19.

In terms of availability of treatment and vaccination, 48.1 said there is a treatment and $82 \%$ stated that there is no vaccination against COVID- 19 .

Correct answers on the different questions regarding the HCWS knowledge about COVID-19 are shown in Table 3. The HCWs have rarely considered coronavirus disease 2019 and viral respiratory illness are denoted the meaning COVID-19 (27.3\%). However, coronavirus disease 2019 had the highest percentage $(68.5 \%)$ as solely the meaning of COVID-19. $78.5 \%$ of the HCWs identified the mode of transmission. Most HCWs were able to identify the correct answers to the symptoms and incubation period of the virus $82.9 \%$ and $96.4 \%$, respectively. Only $22.5 \%$ of participants reported the correct source of COVID-19 when discovered in China, Seafood wholesale market. The participants identified correctly the way of prevention, availability of vaccine against COVID-19, and COVID-19 is the same as MERS-CoV, in a percent of $91.5 \%, 82 \%$, and $74.3 \%$ respectively.

Table 4 demonstrates the difference in the median of the overall score for correct responses of the HCWs knowledge about COVID-19 by demographic factors. The median of the overall score varied significantly by Profession ( $P$.

Table 3. Correct answers on different questions regarding the HCWS knowledge about COVID-19.

\begin{tabular}{|c|c|c|}
\hline Question & Correct answer & $\%$ \\
\hline & Coronavirus disease 2019 & 68.5 \\
\hline \multirow[t]{2}{*}{ What is COVID_19 } & Viral respiratory illness & 2.5 \\
\hline & All answers are correct & 27.3 \\
\hline Mode of transmission & Droplet \& Contact & 78.5 \\
\hline Symptoms & All answers are correct & 82.9 \\
\hline Incubation period & 2 - 14 days & 96.4 \\
\hline Source of COVID-19 when it was discovered in China & Seafood wholesale market & 22.5 \\
\hline Prevention & All answers are correct & 91.5 \\
\hline Is COVID-19 same as MERS-CoV? & No & 74.3 \\
\hline Mortality rate & 3 & 44.6 \\
\hline Availability of treatment & No & 32.1 \\
\hline Availability of Vaccination & No vaccine & 82.0 \\
\hline
\end{tabular}


Table 4. The difference in the median of the overall score for correct responses of the HCWs knowledge about COVID-19 by demographic factors.

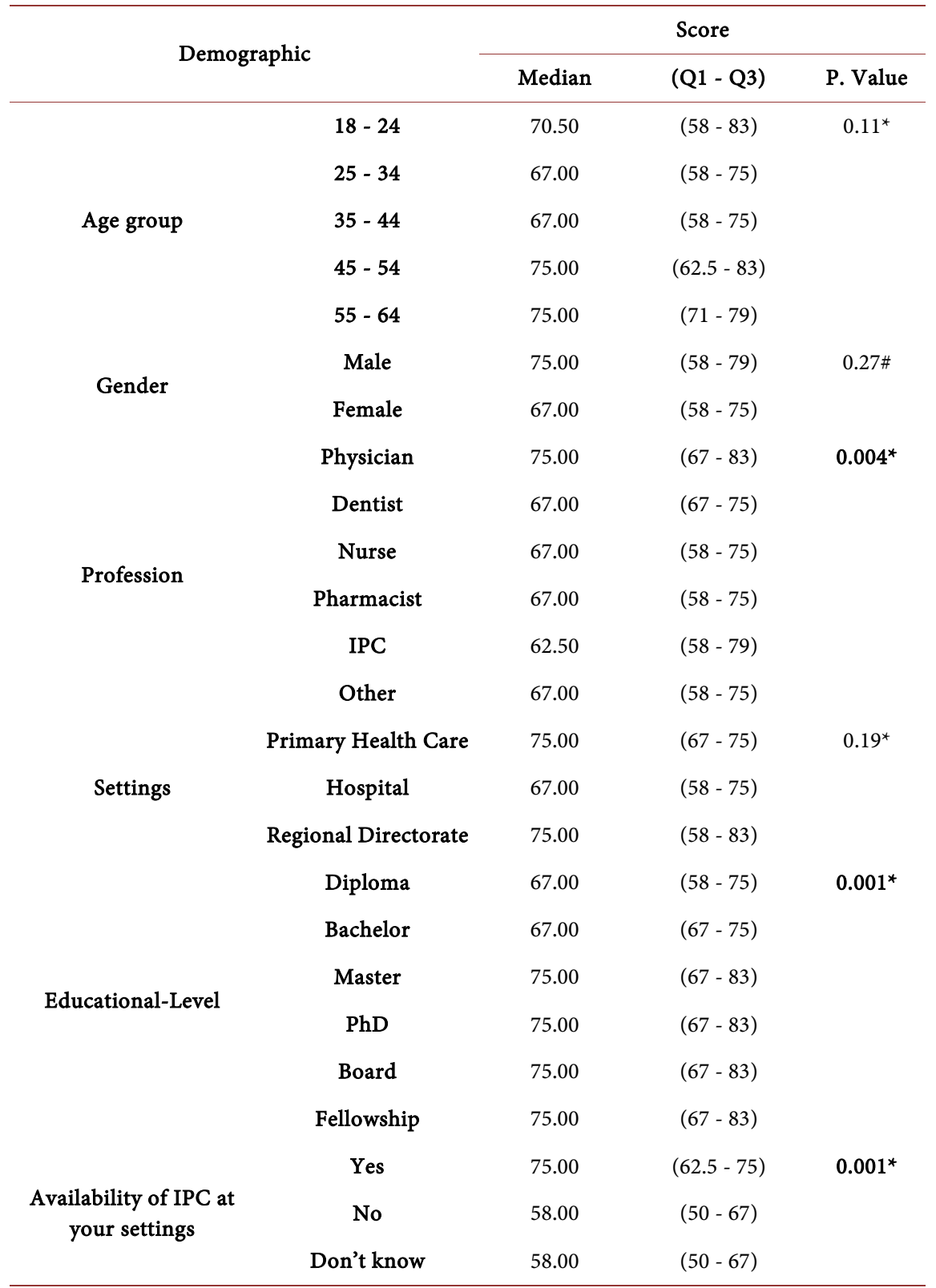

*Kruskal-Wallis, Test \# Mann-Whitney Test, Q1-Q3: first and third quartiles.

value $=0.004)$, educational level $(\mathrm{P}$. value $=0.001)$, and availability of the IPC department at the work of place $(P$. value $=0.001)$.

Variables associated with an overall score of knowledge were analyzed using Robust regression analysis, Table 5. Profession, educational level, and availability of the IPC department were statistically significant factors associated with the overall score in Univariate analysis. In multivariate analysis, Profession $(\mathrm{P}=$ $0.033)$, educational level $(\mathrm{P}=0.034)$ and availability of IPC department $(\mathrm{P}=$ 0.006) were also statistically significant. The score of physicians was 4.45 times higher than the score of other HCWs $(\mathrm{B}=4.45, \mathrm{CI}=0.36-8.52, \mathrm{P}=0.033)$. 
Table 5. Variable associated with the overall knowledge score.

\begin{tabular}{|c|c|c|c|c|c|c|c|}
\hline \multirow[b]{2}{*}{ Factor } & \multicolumn{5}{|c|}{ Univariate analysis } & \multicolumn{2}{|c|}{ Multivariate analysis } \\
\hline & N (\%) & B & $(95 \% \mathrm{CI})$ & P. Value & B & $(95 \% \mathrm{CI})$ & P. Value \\
\hline \multicolumn{8}{|l|}{ Profession } \\
\hline Physician & $92(20.7)$ & 6.909 & $(2.78,11.03)$ & 0.001 & 4.448 & $(0.36,8.52)$ & 0.033 \\
\hline Dentist & $21(4.7)$ & 4.256 & $(-0.66,9.18)$ & 0.090 & 2.815 & $(-2.12,7.75)$ & 0.264 \\
\hline Nurse & $180(40.5)$ & 2.259 & $(-1.07,5.58)$ & 0.185 & 1.662 & $(-1.53,4.86)$ & 0.309 \\
\hline Pharmacist & $26(5.9)$ & 0.329 & $(-5.89,6.55)$ & 0.917 & 1.018 & $(-5.36,7.40)$ & 0.755 \\
\hline IPC & $12(2.7)$ & -4.696 & $(-15.82,6.43)$ & 0.408 & -4.127 & $(-14.28,6.02)$ & 0.426 \\
\hline Other & $113(25.5)$ & 1 & & & 1 & & \\
\hline \multicolumn{8}{|c|}{ Educational Level } \\
\hline Fellowship & $14(3.1)$ & 11.420 & $(5.59,17.24)$ & 0.000 & 6.665 & $(0.51,12.81)$ & 0.034 \\
\hline Board & $18(4)$ & 9.578 & $(3.95,15.20)$ & 0.001 & 5.769 & $(-0.74,12.28)$ & 0.083 \\
\hline $\mathrm{PhD}$ & $10(2.2)$ & 9.134 & $(2.64,15.61)$ & 0.006 & 5.866 & $(-1.05,12.78)$ & 0.097 \\
\hline Master & $57(12.7)$ & 7.186 & $(2.34,12.02)$ & 0.004 & 3.974 & $(-1.20,9.15)$ & 0.133 \\
\hline Bachelor & $222(49.6)$ & 4.566 & $(1.38,7.75)$ & 0.005 & 2.656 & $(-0.25,5.56)$ & 0.073 \\
\hline Diploma & $127(28.3)$ & 1 & & & 1 & & \\
\hline \multicolumn{8}{|c|}{$\begin{array}{l}\text { Availability of IPC } \\
\text { at your settings }\end{array}$} \\
\hline Yes & $408(91.3)$ & 14.113 & $(6.20,22.01)$ & 0.000 & 10.927 & $(3.20,18.65)$ & 0.006 \\
\hline No & $18(4)$ & 2.778 & $(-8.18,13.74)$ & 0.620 & 1.269 & $(-9.53,12.07)$ & 0.818 \\
\hline Don't know & $21(4.7)$ & 1 & & & 1 & & \\
\hline
\end{tabular}

Compared with a score of HCWs who hold diploma degree, HCWs who have fellowship were 6.66 higher $(\mathrm{B}=6.66, \mathrm{CI}=0.51-12.81, \mathrm{P}=0.034)$. The score of HCWs who have the IPC department and aware about it was 10.92 times higher than those who either didn't have or didn't know $(B=10.92, C I=3.20-18.65, P$ $=0.006$ ).

The source of information where the respondents heard about COVID-19 is demonstrated in Figure 1. Approximately $33.2 \%$ of the HCWs have heard about COVID-19 from $\mathrm{MOH}$ information channels, which represent the majority. Media (30.5\%) ranked the second more source of information about COVID-19. Social media and place of work showed $22.9 \%$ and $12.2 \%$, respectively as another source of information. However, only $1.1 \%$ of the respondents reported the source of the information was from their colleagues.

\section{Discussion}

To the best of our knowledge, this is the first study that evaluates the knowledge level of HCWs regarding the current public health issue COVID-19 in Najran city, the southern province of Saudi Arabia. Our study found that the overall knowledge in the HCWs was intermediate (moderate), however, their knowledge 


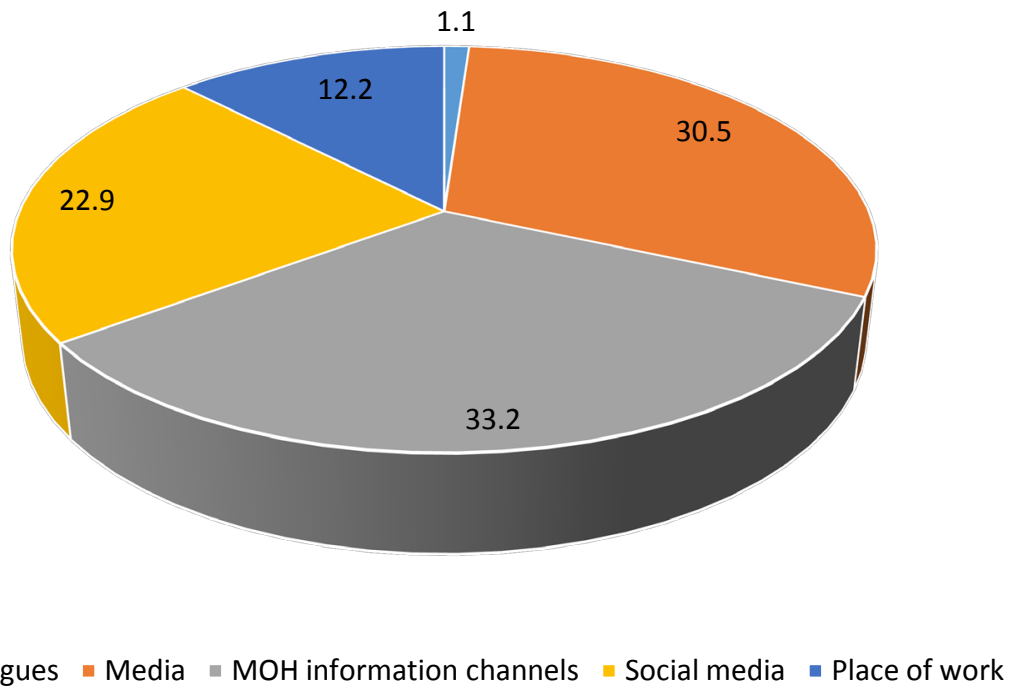

- Colleagues $\approx$ Media $\backsim \mathrm{MOH}$ information channels $\backsim$ Social media $\quad$ Place of work

Figure 1. The source of information where did the participants heard about COVID-19.

was low about the source of COVID-19 when it was discovered in China, the mortality rate, and the presence of the treatment. Variability in the knowledge was found among the HCWs based on the profession, educational level, and presence of the IPC department in their healthcare facilities. Therefore, these results demonstrated that the HCWs are still in need of more efforts to increase their knowledge about COVID-19 as they represent the frontline against this disease.

The overall knowledge score in the HCWs of this study was $67 \%$ which is very close to the recent study assessing the awareness of COVID-19 diseases among healthcare professionals and students in the Mumbai Metropolitan Region in India which was $71.2 \%$ [38]. In 2019, Asaad and colleagues reported that the HCWs in PHC and hospitals at Najran in Saudi Arabia showed a high level of knowledge and positive attitude toward the MERS-CoV [39], nevertheless, the results of a similar survey carried out in HCWs from $\mathrm{MOH}$ suggested poor knowledge about MERS-CoV disease [40].

$\mathrm{MOH}$ posts guidelines and evidence-based information to educate the staff and guide them to follow the safe and proper strategies during such a public health crisis. Depending on the $\mathrm{MOH}$ as the main source of information, is expected to provide staff with adequate knowledge. However, the overall knowledge of staff suggests more efforts are needed to educate staff about this pandemic. This could be explained by the fact that only one-third of the study participants reported that their most source of the information was $\mathrm{MOH}$ information channels out of five various sources. In contrast, other studies revealed that their participants used social media and other sources as the main sources of the information [39] [41] [42] [43].

In the present study, most participants had high knowledge about the mode of transmission (78.5\%), symptoms $(82.9 \%)$, the incubation period $(96.4 \%)$, the way of prevention (91.5\%), is the MERS-CoV same as COVID-19 (74.3\%) and 
availability of vaccine (82.0\%). Similar findings have reported previously [39] [44].

On the other hand, the level of the knowledge level among HCWs was low on only three questions. Just $22.5 \%$ of the study participants were able to identify the source of COVID-19 when it was first found in China. The reasons behind this were; various sources of information the HCWs were followed and; some pictures that were posted in the social media showing bats and some animals as a source of the infection. Approximately 44.5\% of HCWs answered the question related to the mortality rate correctly, whereas it was reported that the global mortality rate was about $3 \%$ [45]. In KSA, the mortality rate was less than $1 \%$ since the emerging COVID-19. Besides, nearly $32 \%$ of participants knew that there was no treatment to cure the infection caused by COVID-19. Similarly, in a study conducted in the north region of KSA found that roughly $35 \%$ of the study participants identified there was no drug treatment for MERS-CoV [46].

This study revealed that the knowledge level of participants was variable. Physicians, for example, had high median scores of knowledge (75\%) compared to Dentists (67\%), Nurse (67\%), Pharmacists (67\%), IPC staff (62\%), and other HCWs (67\%). HCWs who had post-graduate qualifications showed better knowledge than those who had a bachelor or diploma degree. Furthermore, the median scores of HCWs who knew availability of IPC department in their settings were higher than those who reported that they did not have IPC department in their working place and those who had not known If the IPC available at their settings, $75 \%, 58 \%$, and 58\%, respectively. Similar findings have been reported before [39].

It is important to ensure the availability of the HCWs mentioned above during implementation of the intervention programs.

In terms of demographic variables that were statistically significantly associated with an overall median score of healthcare staffs knowledge toward the COVID-19; profession, educational level, and availability of the IPC department in the workplace were the only three significant variables. A study conducted in the Al Jouf region reported similar variables (gender, educational level, and occupation) associated with an overall score [46]. However, Khan et al. stated that gender and experience were the only two statistically significant demographic variables associated with the overall mean score of the knowledge of the HCWs. [44]. Although other research does not support the association of gender with the knowledge and attitude of HCWs [47], which agrees with our results.

This study has some limitations. First, the possibility of recall and misclassification bias, because it was questionnaire based study. Second, this study was conducted in a single region in the KSA, thus we can't generalize our findings to the entire KSA.

\section{Conclusion}

The findings of this study demonstrated an intermediate level of the knowledge 
of HCWs about COVID-19. Yet there are areas where the HCWs have low level of knowledge regarding COVID-19 such as the mortality rate, the source of COVID-19 and the availability of the treatment. Intervention programs are urgently needed to raise the knowledge of HCWs about this global public health issue. National wide study assessing the knowledge of the healthcare providers is also important to ensure that the HCWs are knowledgeable about the COVID-19, and ensuring the HCWs are receiving the information from $\mathrm{MOH}$ which is evidence-based source.

\section{Acknowledgements}

We would like to thank all individuals who facilitated the distribution of the questionnaire. We are also thankful for Dr. Hassan Kasim Haridi for revision the part of the results.

\section{Funding}

Our study did not receive funding support.

\section{Conflicts of Interest}

The authors declare no conflicts of interest regarding the publication of this paper.

\section{References}

[1] Tyrrell, D.A.J. and Bynoe, M.L. (1965) Cultivation of a Novel Type of Common Cold Virus in Organ Culture. British Medical Journal, 1, 1467-1470. https://doi.org/10.1136/bmj.1.5448.1467

[2] Hendley, J.O., Fishburne, H.B. and Gwaltney, J.M. (1972) Coronavirus Infections in Working Adults. Eight-Year Study with $229 \mathrm{E}$ and OC43. The American Review of Respiratory Disease, 105, 805-811.

[3] Keyaerts, E., Li, S., Vijgen, L., Rysman, E., Verbeeck, J., et al. (2009) Antiviral Activity of Chloroquine against Human Coronavirus OC43 Infection in Newborn Mice. Antimicrobial Agents and Chemotherapy, 53, 3416-3421. https://doi.org/10.1128/AAC.01509-08

[4] Poutanen, S.M. (2018) Human Coronaviruses. In: Principles and Practice of Pediatric Infectious Diseases, Elsevier, Amsterdam, 1148-1152.e3. https://doi.org/10.1016/B978-0-323-40181-4.00222-X

[5] Zhu, N., Zhang, D., Wang, W., Li, X., Yang, B., Song, J., Zhao, X., Huang, B., Shi, W., Lu, R. and Niu, P. (2020) A Novel Coronavirus from Patients with Pneumonia in China, 2019. The New England Journal of Medicine, 382, 727-733. https://doi.org/10.1056/NEJMoa2001017

[6] Lee, K.H., Yoo, S.G., Cho, Y., La, Y., Han, S.H., Kim, M.S., Choi, J.S., Kim, S.I., Kim, Y.S., Min, Y.H. and Cheong, J.W. (2019) Characteristics of Community-Acquired Respiratory Viruses Infections Except Seasonal Influenza in Transplant Recipients and Non-Transplant Critically Ill Patients. Journal of Microbiology, Immunology and Infection. https://doi.org/10.1016/j.jmii.2019.05.007

[7] Su, S., Wong, G., Shi, W., Liu, J., Lai, A.C., Zhou, J., Liu, W., Bi, Y. and Gao, G.F. (2016) Epidemiology, Genetic Recombination, and Pathogenesis of Coronaviruses. 
Trends in Microbiology, 24, 490-502. https://doi.org/10.1016/j.tim.2016.03.003

[8] Zhong, N.S., Zheng, B.J., Li, Y.M., Poon, L.L., Xie, Z.H., Chan, K.H., Li, P.H., Tan, S.Y., Chang, Q., Xie, J.P. and Liu, X.Q. (2003) Epidemiology and Cause of Severe Acute Respiratory Syndrome (SARS) in Guangdong, People's Republic of China, in February, 2003. The Lancet, 362, 1353-1358.

https://doi.org/10.1016/S0140-6736(03)14630-2

[9] Drosten, C., Günther, S., Preiser, W., Van Der Werf, S., Brodt, H.R., Becker, S., Rabenau, H., Panning, M., Kolesnikova, L., Fouchier, R.A. and Berger, A. (2003) Identification of a Novel Coronavirus in Patients with Severe Acute Respiratory Syndrome. New England Journal of Medicine, 348, 1967-1976. https://doi.org/10.1056/NEJMoa030747

[10] Cyranoski, D. (2003) China Joins Investigation of Mystery Pneumonia. Nature, 422, 459. https://doi.org/10.1038/422459b

[11] Assiri, A., Al-Tawfiq, J.A., Al-Rabeeah, A.A., Al-Rabiah, F.A., Al-Hajjar, S., et al. (2013) Epidemiological, Demographic, and Clinical Characteristics of 47 Cases of Middle East Respiratory Syndrome Coronavirus Disease from Saudi Arabia: A Descriptive Study. The Lancet Infectious Diseases, 13, 752-761.

https://doi.org/10.1016/S1473-3099(13)70204-4

[12] Zumla, A., Hui, D.S. and Perlman, S. (2015) Middle East Respiratory Syndrome. The Lancet, 386, 995-1007. https://doi.org/10.1016/S0140-6736(15)60454-8

[13] Wuhan Municipal Health Commission (2019) Report of Clustering Pneumonia of Unknown Etiology in Wuhan City.

[14] Coronaviridae Study Group of the International Committee on Taxonomy of Viruses (2020) The Species Severe Acute Respiratory Syndrome-Related Coronavirus: Classifying 2019-nCoV and Naming It SARS-CoV-2. Nature Microbiology, 5, 536-544. https://doi.org/10.1038/s41564-020-0695-Z

[15] WHO Director-General Announced "COVID-19" as the Name of This New Disease on 11 February 2020.

[16] TedrosAdhanomGhebreyesus (2020) Director-General of the WHO Announces That the COVID-19 Outbreak Is a Pandemic.

[17] Saudi Arabia Announces First Case of Coronavirus. Arabnews.com. https://www.arabnews.com/node/1635781/saudi-arabia

[18] Saudi Arabia's Health Ministry. COVID 19 Dashboard. Saudi Arabia. https://covid19.moh.gov.sa

[19] WHO Report (2003) Severe Acute Respiratory Syndrome (SARS) Multi-Country Outbreak Update 6. https://doi.org/10.1183/09031936.03.00035403

[20] Honigsbaum, M. (2019) The Pandemic Century: One Hundred Years of Panic, Hysteria and Hubris. Oxford University Press, Oxford.

[21] WHO Disease Outbreak Report (2003) Severe Acute Respiratory Syndrome (SARS) Multi-Country Outbreak Update. https://www.who.int/csr/don/2003_03_16/en

[22] Robert, M.T. (2004) The Experience of the 2003 SARS Outbreak as a Traumatic Stress among Frontline Healthcare Workers in Toronto: Lessons Learned. Philosophical Transactions. Biological Sciences, 359, 1117-1125. https://doi.org/10.1098/rstb.2004.1483

[23] Chan, J.F., Yuan, S., Kok, K.H., To, K.K., Chu, H., Yang, J., Xing, F., Liu, J., Yip, C.C., Poon, R.W. and Tsoi, H.W. (2020) A Familial Cluster of Pneumonia Associated with the 2019 Novel Coronavirus Indicating Person-to-Person Transmission: A Study of a Family Cluster. The Lancet, 395, 514-523. 
https://doi.org/10.1016/S0140-6736(20)30154-9

[24] Li, Q., Guan, X., Wu, P., Wang, X., Zhou, L., Tong, Y., Ren, R., Leung, K.S., Lau, E.H., Wong, J.Y. and Xing, X. (2020) Early Transmission Dynamics in Wuhan, China, of Novel Coronavirus-Infected Pneumonia. New England Journal of Medicine, 382, 1199-1207.

[25] Wang, D., Hu, B., Hu, C., Zhu, F., Liu, X., Zhang, J., Wang, B., Xiang, H., Cheng, Z., Xiong, Y. and Zhao, Y. (2020) Clinical Characteristics of 138 Hospitalized Patients with 2019 Novel Coronavirus-Infected Pneumonia in Wuhan, China. JAMA, 323, 1061-1069. https://doi.org/10.1001/jama.2020.1585

[26] Chang, D., Lin, M., Wei, L., Xie, L., Zhu, G., Cruz, C.S. and Sharma, L. (2020) Epidemiologic and Clinical Characteristics of Novel Coronavirus Infections Involving 13 Patients outside Wuhan, China. JAMA. https://doi.org/10.1001/jama.2020.1623

[27] Carlos, W.G., Dela Cruz, C.S., Cao, B., Pasnick, S. and Jamil, S. (2020) Novel Wuhan (2019-nCoV) Coronavirus. American Journal of Respiratory and Critical Care Medicine, 201, 7-8. https://doi.org/10.1164/rccm.2014P7

[28] Biscayart, C., Angeleri, P., Lloveras, S., Chaves, T.D., Schlagenhauf, P. and Rodríguez-Morales, A.J. (2020) The Next Big Threat to Global Health? 2019 Novel Coronavirus (2019-nCoV): What Advice Can We Give to Travellers? Interim Recommendations January 2020, from the Latin-American Society for Travel Medicine (SLAMVI). Travel Medicine and Infectious Disease, 33, Article ID: 101567. https://doi.org/10.1016/j.tmaid.2020.101567

[29] Docea, A.O., Tsatsakis, A., Albulescu, D., Cristea, O., Zlatian, O., Vinceti, M., Moschos, S.A., Tsoukalas, D., Goumenou, M., Drakoulis, N., Dumanov, J.M., Tutelyan, V.A., Onischenko, G.G., Aschner, M., Spandidos, D.A. and Calina, D. (2020) A New Threat from an Old Enemy: Re-Emergence of Coronavirus (Review). International Journal of Molecular Medicine, 45, 1631-1643. https://doi.org/10.3892/ijmm.2020.4555

[30] Singh, V., Lehl, G.K., Talwar, M. and Luthra, A. (2020) The Novel Coronavirus and Challenges for General and Paediatric Dentists. Occupational Medicine. https://doi.org/10.1093/occmed/kqaa055

[31] Ramphul, K. and Mejias, S.G. (2020) Coronavirus Disease: A Review of a New Threat to Public Health. Cureus, 12, e7276. https://doi.org/10.7759/cureus.7276

[32] World Health Organization (WHO). Coronavirus Disease (COVID-19) Advice for the Public.

https://www.who.int/emergencies/diseases/novel-coronavirus-2019/advice-for-public

[33] Craven, J. (2020) COVID-19 Vaccine Tracker. Regulatory Affairs Professionnals Society.

[34] Gao, Q., Bao, L., Mao, H., Wang, L., Xu, K., Yang, M., Li, Y., Zhu, L., Wang, N., Lv, Z. and Gao, H. (2020) Development of an Inactivated Vaccine Candidate for SARS-CoV-2. Science.

[35] Al-Noaemi, M.C. and Hammoodi, A.-H.M. (2020) COVID-19 and Hydroxychloroquine relationship in the Past, Present, and Future. The Pharma Innovation Journal, 9, 944-948.

[36] Al-Noaemi, M.C. and ChyadHammoodi, A.M. (2020) Drug Repositioning for the Prophylaxis and Treatment of COVID-19. Journal of Cardiology Research Reviews \& Reports, 2, 1-6.

[37] Saqlain, M., Munir, M.M., Rehman, S.U., Gulzar, A., Naz, S., Ahmed, Z., Tahir, A.H. and Mashhood, M. (2020) Knowledge, Attitude, Practice and Perceived Barriers among Healthcare Professionals Regarding COVID-19: A Cross-Sectional 
Survey from Pakistan. https://doi.org/10.1101/2020.04.13.20063198

[38] Modi, P.D., Nair, G., Uppe, A., Modi, J., Tuppekar, B., Gharpure, A.S. and Langade, D. (2020) COVID-19 Awareness among Healthcare Students and Professionals in Mumbai Metropolitan Region: A Questionnaire-Based Survey. Cureus, 12, e7514. https://doi.org/10.7759/cureus.7514

[39] Asaad, A.M., El-Sokkary, R., Alzamanan, M.A. and Shafei, M.E. (2020) Knowledge and Attitudes towards Middle East Respiratory Syndrome-Coronavirus (MERS-CoV) among Health Care Workers in South-Western Saudi Arabia. Eastern Mediterranean Health Journal, 26, 435-442. https://doi.org/10.3844/ajidsp.2019.37.43

[40] Alsahafi, A.J. and Cheng, A.C. (2016) Knowledge, Attitudes and Behaviours of Healthcare Workers in the Kingdom of Saudi Arabia to MERS Coronavirus and Other Emerging Infectious Diseases. International Journal of Environmental Research and Public Health, 13, 1214. https://doi.org/10.3390/ijerph13121214

[41] Kharma, M.Y., Alalwani, M.S., Amer, M.F., Tarakji, B. and Aws, G. (2015) Assessment of the Awareness Level of Dental Students toward Middle East Respiratory Syndrome-Coronavirus. Journal of International Society of Preventive \& Community Dentistry, 5, 163. https://doi.org/10.4103/2231-0762.159951

[42] Almutairi, K.M., Al Helih, E.M., Moussa, M., Boshaiqah, A.E., Saleh Alajilan, A., Vinluan, J.M. and Almutairi, A. (2015) Awareness, Attitudes, and Practices Related to Coronavirus Pandemic among Public in Saudi Arabia. Family \& Community Health, 38, 332-340. https://doi.org/10.1097/FCH.0000000000000082

[43] Al-Hazmi, A., Gosadi, I., Somily, A., Alsubaie, S. and Saeed, A.B. (2018) Knowledge, Attitude and Practice of Secondary Schools and University Students toward Middle East Respiratory Syndrome Epidemic in Saudi Arabia: A Cross-Sectional Study. Saudi Journal of Biological Sciences, 25, 572-577. https://doi.org/10.1016/j.sjbs.2016.01.032

[44] Khan, M.U., Shah, S., Ahmad, A. and Fatokun, O. (2014) Knowledge and Attitude of Healthcare Workers about Middle East Respiratory Syndrome in Multispecialty Hospitals of Qassim, Saudi Arabia. BMC Public Health, 14, Article No. 1281. https://doi.org/10.1186/1471-2458-14-1281

[45] WHO COVID-19. https://www.who.int/dg/speeches/detail/who-director-general-s-opening-remarks-a t-the-media-briefing-on-covid-19---3-march-2020

[46] Nooh, H.Z., Alshammary, R.H., Alenezy, J.M., Alrowaili, N.H., Alsharari, A.J., Alenzi, N.M. and Sabaa, H.E. (2020) Public Awareness of Coronavirus in Al-Jouf Region, Saudi Arabia. Journal of Public Health, 1-8. https://doi.org/10.1007/s10389-020-01209-y

[47] Isara, A.R. and Akpodiete, A. (2014) Concerns about the Knowledge and Attitude of Multidrug-Resistant Tuberculosis among Health Care Workers and Patients in Delta State, Nigeria. Nigerian Journal of Clinical Practice, 18, 664-669. 